\title{
Pesquisas genéticas, prognósticos morais e discriminação genética: um estudo de caso sobre traço falciforme
}

\author{
| ${ }^{1}$ Cristiano Guedes, ${ }^{2}$ Danielle Reis |
}

Resumo: O estudo analisou os debates, no período de 2000 a 2010, no Conselho Nacional de Saúde (CNS) e na Comissão Intersetorial de Vigilância Sanitária e Farmacoepidemiologia (CIVSF), sobre os temas da vigilância sanitária e articulação com o Conselho Consultivo da Agência Nacional de Vigilância Sanitária (Anvisa). A pesquisa documental, de natureza qualitativa, que analisou 163 atas de reuniōes do CNS e da CIVSF, e demais documentos a elas relacionados, buscou reunir informaçôes sobre o contexto político-institucional e as interfaces e conexôes entre as três instâncias. Observouse baixa inserção do tema "vigilância sanitária" na pauta do CNS e uma atuação insuficiente da CIVSF para o fortalecimento desse debate. Conclui-se pela fragilidade de integração entre o Conselho Consultivo da Anvisa e as instâncias de controle social no Sistema Único de Saúde. Esse resultado é fruto de dificuldades de comunicação interinstitucional e da baixa inserção da vigilância sanitária no SUS, historicamente construída.

> Palavras-chave: ética em pesquisa; discriminação genética; traço falciforme; esportes.

\author{
1 Universidade de Brasília; \\ Instituto de Bioética, Direitos \\ Humanos e Gênero. Brasília-DF, \\ Brasil. Endereço eletrônico: \\ c.bsb.br@gmail.com \\ ${ }^{2}$ Ministério Público Federal. \\ Brasília-DF, Brasil. Endereço \\ eletrônico: danielle.reis@mpt. \\ gov.br
}

Recebido em: 12/02/2015 Aprovado em: 22/05/2015 


\section{Introdução ${ }^{1}$}

A ética em pesquisa se configura como uma arena de intensos debates desde que, em 1996, uma exitosa regulamentação brasileira definiu princípios a serem adotados na investigação científica com pessoas. A resolução criada na década de 1990 não foi a primeira tentativa brasileira de estabelecer parâmetros éticos para estudos nas diferentes áreas do saber. A primeira tentativa foi em 1988, por meio da Resolução no 1 do Conselho Nacional de Saúde, documento pioneiro na indicação de cuidados éticos e da necessidade de submissão de propostas de pesquisa à avaliação de um comitê (BRASIL, 1988a; COSTA, 2008). Apesar do pioneirismo, o documento criado em 1988 não se tornou um referencial para a comunidade nacional de pesquisadores, pois não existiam comitês em quantidade suficiente para avaliação dos projetos de pesquisa; faltavam recursos humanos capacitados para avaliação dos projetos; o texto da resolução era voltado às pesquisas médicas; e havia permissões controversas na resolução pioneira, como a que dispensava pesquisadores de submeter seus projetos a avaliação desde que pertencessem a programas de pós-graduação com o conceito máximo de avaliação na CAPES (GUILHEM; GRECO, 2008). Foi somente na década seguinte, com a Resolução o 196/96, que o Conselho Nacional de Saúde determinou diretrizes éticas a serem cumpridas em estudos científicos envolvendo pessoas. Esta resolução visava superar os limites de sua antecessora e ser eficaz na proteção aos direitos das pessoas participantes de pesquisas.

Em 1995, foi instituído no Conselho Nacional de Saúde um grupo de trabalho composto por especialistas na área da ética em pesquisa e representantes da sociedade civil que seriam responsáveis pela elaboração de uma resolução fundamentada teoricamente e capaz de prever um sistema de revisão ética nacional que abrangesse todas as áreas do saber. Esse grupo foi formado predominantemente por pessoas das áreas da saúde, o que pode explicar parcialmente o fato de a Resolução no 196/96 priorizar a realidade das pesquisas biomédicas e ser pouco adequada às pesquisas qualitativas no âmbito das Ciências Humanas e Sociais. Tanto essa resolução como sua versão atualizada, a Resolução no 466/2012, foram responsáveis pelo surgimento de um robusto sistema de revisão ética com abrangência nacional e participação de pesquisadores de diferentes campos do saber, apesar de ambas possuírem limites em seu conteúdo e processo de criação. 
Os limites das resoluções e do sistema de revisão ética dos projetos de pesquisa vigentes no Brasil têm sido explorados principalmente em debates e publicações de pesquisadores das Ciências Humanas e Sociais. Há descontentamento em relação à imposição de regras de conduta e protocolos que não se adequam às especificidades de estudos qualitativos (VÍCTORA et al., 2004; DINIZ et al., 2008; FLEISCHER; SCHUCH, 2010; OLIVEIRA; GUEDES, 2013; MINAYO; GUERRIERO, 2014). As queixas são variadas e envolvem desde a apresentação de um projeto de pesquisa completo, com a descrição de todas as etapas metodológicas, até a imposição de meios específicos voltados à proteção dos participantes da pesquisa, como é o caso do Termo de Consentimento Livre e Esclarecido (TCLE), ou mesmo a proibição de divulgar nomes das pessoas pesquisadas, uma vez que a preservação do anonimato é descrita como uma garantia ética que preveniria danos aos participantes. ${ }^{2} \mathrm{O}$ principal desafio da resolução vigente e seus meios de controle é reconhecer a diversidade de metodologias de pesquisa fora do âmbito biomédico e realizar um exercício de tolerância epistemológica capaz de evitar o julgamento moral de pesquisadores que, embora compromissados com a preservação dos direitos dos participantes de suas pesquisas, não consideram necessário o cumprimento integral do que determina a resolução restritiva e seus guardiōes.

A maior parte das publicações que analisam os limites do sistema de revisão ética no Brasil se concentra em explorar suas exigências abusivas para estudos realizados fora do âmbito biomédico. A literatura não tem discutido como a Resolução no 466/2012 pode encontrar resistência também entre pesquisadores das áreas biomédicas, que poderíamos denominar de "críticos endógenos do sistema", visto que a resolução foi prioritariamente criada para eles, que descumprem ou seguem parcialmente as diretrizes estabelecidas.

Este artigo é voltado à apresentação de um caso no âmbito da medicina esportiva em que não foram adotados cuidados éticos em relação à proteção de direitos da pessoa envolvida no estudo. Com base no caso apresentado, é possível argumentar que podem existir pesquisas biomédicas que, feitas sob a justificativa de se tratar de procedimentos de assistência em saúde, negligenciam os requisitos éticos previstos em investigações científicas. A medicina esportiva é um campo onde nem sempre as pesquisas estão voltadas à assistência em saúde dos participantes, como é o caso da adoção de testes genéticos para avaliação de atletas. 
Submeter atletas a investigaçōes em saúde é uma prática corriqueira em clubes e confederações esportivas tanto no Brasil como em outros países. Esse tipo de rotina contém desdobramentos éticos ainda pouco discutidos. $\mathrm{O}$ atendimento em saúde tem, em princípio, a meta de investigar as condições físicas dos atletas para o fornecimento de assistência capaz de tratar e prevenir doenças, bem como melhorar o desempenho esportivo. Nesse contexto, a medicina esportiva tem se aproximado cada vez mais da genética. Com os avanços da genética e suas descobertas na última década, a medicina esportiva tem feito uso crescente de testes genéticos para avaliação de atletas profissionais (McNAMEE et al., 2009). A adoção de testes genéticos no meio esportivo, porém, levanta dilemas éticos tendo em vista os usos que se podem fazer das informações obtidas. Os resultados dos testes genéticos podem tanto servir para o fornecimento de assistência e cuidados imediatos em saúde, capazes de evitar agravos à integridade física, como revelar prognósticos de doenças ou dar margem a especulaçóes sobre o desempenho futuro do atleta em treinamentos e competições (WAGNER, 2013). Sendo assim, uma questão no debate contemporâneo é: qual uso deve ser feito da informação sensível obtida por meio de testes genéticos aplicados em atletas?

A informação genética sobre características herdadas por uma pessoa pode ser classificada como sensível. Neste artigo, considera-se informação sensível aquela obtida por meio de pesquisa médica sobre dados pessoais com potencial de gerar discriminação e prejuízos às pessoas (PAZELLO; KAMEDA, 2013). Entre essas informações, podem ser mencionadas desde doenças infectocontagiosas, como aids, até doenças genéticas, como anemia falciforme e Huntington (THOMAS, 2012; LEMKE, 2013). O uso sem critérios da informação sensível sobre a saúde de pessoas submetidas a testes pode ocasionar discriminação em cenários variados, como trabalho, escola e empresas de planos de saúde, sobretudo em países como o Brasil, onde são frágeis ou inexistem políticas claras e suficientes para preservar a identidade das pessoas em relação a suas informações sensíveis (GUEDES; DINIZ, 2009; PAZELLO; KAMEDA, 2013). Neste artigo, será discutido o caso de uma atleta impedida de participar da seleção brasileira após ser identificada com o traço falciforme por meio de uma pesquisa médica realizada por profissional da Confederação Brasileira de Futebol (CBF). Defendemos o argumento de que a pesquisa sobre o traço falciforme não foi voltada à assistência em saúde, pois não existia uma doença que requereria tratamento e impediria a atleta de jogar. 
O traço falciforme é uma característica genética que não pode ser considerada uma doença nem um impeditivo à prática de atividades esportivas. Pessoas com traço falciforme são aquelas com hemoglobinas AS e capazes de fazer o transporte satisfatório de oxigênio no organismo (BRASIL, 2009). Entretanto, existem pessoas com hemoglobinas SS, que possuem anemia falciforme, doença responsável pela dificuldade em transportar oxigênio. A anemia falciforme pode ocasionar manifestações clínicas com diferentes graus de gravidade e, nesses casos, a prática de atividades esportivas pode representar um risco à vida (ZAGO, 2001). A opinião sobre a prática de esportes por pessoas com o traço falciforme não é consensual na literatura, existindo tanto pesquisadores que a defendem como os que a criticam, dados os riscos da atividade física à vida de atletas (PEARSON, 1989; ACSM, 1997; NIH, 2002; BERGERON et al., 2005; BRASIL, 2009; QUICK, 2012). No Brasil, o Ministério da Saúde, por meio de documento publicado em 2009 e com base em reunião realizada com um grupo de especialistas em herança falciforme, posiciona-se favorável à prática de exercícios físicos por pessoas com esse traço. O ministério, além disso, considera que "não é necessária" a realização de testes para identificação de praticantes de esportes, independentemente de serem esportistas amadores ou profissionais (BRASIL, 2009, p. 31).

$\mathrm{Na}$ literatura internacional, existem relatos sobre pessoas que sofreram discriminação por causa de suas características genéticas descobertas por meio de testes e divulgadas sem cuidados éticos adequados. Esses casos de discriminação podem ocorrer principalmente na vida laboral e no acesso aos planos de saúde e seguros de vida, ocasionando desigualdades nas relações interpessoais e dificuldade de inserção no mercado de trabalho, sob a justificativa da identificação de marcadores genéticos não direcionados à produtividade e qualidades desejáveis requeridas pelo cargo (DIVER; COHEN, 2001). Apesar de a literatura registrar uma quantidade reduzida de episódios envolvendo esse tipo de discriminação ao redor do mundo, esse fato não pode ser confundido com a ausência desse tipo de injustiça social ou impedir a adoção de medidas regulatórias voltadas a coibir tal ameaça à preservação de direitos (THOMAS, 2012; JOLY et al., 2013; LEMKE, 2013; ROSE, 2013; QUINN; DE PAOR; BLANCK, 2015). No Brasil, um caso de discriminação de atleta do voleibol com traço falciforme foi relatado na Revista Physis em 2007, e ainda são raras as publicaçôes que reportem resultados de pesquisas empíricas sobre o tema que é 
emergente no âmbito das Ciências Sociais (GUEDES; DINIZ, 2007; IRIART; CAPRARA, 2011). O artigo publicado mostrou o uso indevido da informação genética e a eliminação da atleta de um campeonato internacional em decorrência do traço falciforme. O caso foi contestado por instituições de saúde e de defesa de direitos e ganhou repercussão na mídia e em organizações governamentais, como o Ministério da Saúde (BRASIL, 2009). Mais recentemente, em 2010, um novo caso de discriminação por traço falciforme, dessa vez envolvendo uma atleta de futebol, ocorreu no Brasil.

O objetivo deste artigo é analisar as repercussões da pesquisa genética para identificação do traço falciforme sobre a ausência de cuidados éticos voltados à preservação dos direitos de quem se submete aos testes. Após a apresentação da metodologia do estudo, o artigo será dividido em duas partes: 1) apresentação do caso analisado e suas controvérsias no contexto brasileiro; e 2) discussão sobre discriminação genética e reflexão sobre como pesquisas genéticas realizadas no campo da medicina esportiva e sem a finalidade de fornecer assistência em saúde carecem da observância de princípios da ética em pesquisa.

\section{Metodologia}

Este artigo se baseou em pesquisa qualitativa realizada em 2012 em uma cidade da regiāo Nordeste do Brasil. O caso estudado pode ser considerado relevante devido à lacuna, no país, de pesquisas que analisem o uso da informação genética no meio desportivo e as repercussões sociais desse uso na vida de atletas (GUEDES; DINIZ, 2007). Além disso, o caso suscita a necessidade de reavaliar o avanço de programas de rastreio genético sem os devidos fundamentos éticos e a possibilidade de segregação genética no meio esportivo (WAGNER, 2013).

A pesquisa foi realizada em três etapas. A primeira consistiu na análise documental de matérias na mídia que divulgaram o episódio de eliminação da atleta do campeonato. $\mathrm{Na}$ discussão internacional, levanta-se a problemática sobre a amplitude com que o conhecimento público de determinadas características genéticas, divulgadas pelos meios midiáticos, pode contribuir na acentuação de um contexto de discriminação (QUICK, 2012). Na segunda etapa, foram levantados dados no estado de origem da atleta, por meio da realização de entrevistas semiestruturadas com a repórter que acompanhou o caso e com o técnico do clube esportivo estadual no qual a atleta atuou profissionalmente. A 
realização das entrevistas com esses indivíduos possibilitou entender melhor o percurso de eliminação da atleta da seleção brasileira de futebol. As entrevistas foram pautadas pela observância dos cuidados éticos constantes na Resolução no 196/96, do Conselho Nacional de Saúde, e o projeto de pesquisa que originou o presente artigo foi submetido e aprovado por um Comitê de Ética em Pesquisa (CEP). Os entrevistados foram convidados a participar voluntariamente do estudo e esclarecidos, por meio de um termo de consentimento, sobre os objetivos da pesquisa e a preservação do anonimato do conteúdo analisado. Neste artigo, não serão revelados os nomes das pessoas envolvidas no caso, dos profissionais entrevistados e do clube esportivo como medida de preservação de suas identidades.

A última etapa consistiu na análise em profundidade dos dados obtidos por meio do trabalho de campo e da transcrição das entrevistas. Deu-se ênfase às informaçōes dos dados empíricos, objetivando explorar os aspectos éticos que envolveram a realização do teste genético e os desdobramentos da divulgação da informação genética para a vida da atleta. A técnica da análise do discurso foi empregada na busca pela totalidade do texto e pela recuperação das percepções dos sujeitos sobre a significância (MOUTINHO et al., 2014; MINAYO, 2007; ORLANDI, 2001) e as repercussões da pesquisa genética no cotidiano da atleta. Assim, o estudo de caso pode ser considerado central por dois aspectos: contribui na compreensão sobre a persistência do fenômeno da discriminação motivada pela presença do traço falciforme em atletas brasileiros; e discute os desafios éticos de pesquisas com testes genéticos em um país com escassez de profissionais capacitados e sem legislação que proteja o acesso a informações sensíveis das pessoas.

\section{A atleta e sua eliminação da seleção de futebol}

Jogar na seleção brasileira de futebol foi a meta que levou a protagonista deste caso a migrar do interior do país para a capital de seu estado aos 15 anos. Logo nos primeiros dias na capital, a adolescente mostrou sua habilidade em campo e passou a integrar a equipe estadual de um clube onde posteriormente conquistaria títulos de campeonatos regionais, alcançaria visibilidade nacional e participaria de disputas fora do país. Nessas disputas, foi considerada uma das melhores jogadoras da seleção sub-17 ao representar o Brasil em um campeonato sul-americano. Entre as habilidades da jovem, estava sua capacidade de jogar 
numa posição em que existia carência de atletas, uma característica observada logo nas primeiras semanas de treinamento pelo técnico do clube estadual: “[...] eu senti que tinha um futuro, principalmente porque a gente sabia que aqui no país tinha uma dificuldade muito grande de lateral esquerda”. A previsão de "um futuro" de êxito se concretizou e a atleta seguiu jogando da adolescência até o início da fase adulta, quando foi convocada a integrar a seleção brasileira de futebol feminino. Porém, sua trajetória profissional foi suspensa devido ao resultado de um teste genético.

A atleta tinha 19 anos ao receber, em 2010, a convocação da CBF para jogar na seleção feminina adulta na disputa do Campeonato Sul-Americano, que ocorreria no Equador. Como é comum nessas ocasiōes, todas as atletas convocadas ficaram concentradas em um local de treinamento destinado à avaliação das condições físicas e preparação para a disputa. Os exames médicos feitos nas atletas buscavam identificar condições físicas que exigiriam algum tipo de assistência em saúde, além de atestar a existência de condições adequadas para as disputas. No âmbito da medicina esportiva, a adoção de testes genéticos é uma prática recente, possivelmente resultado dos avanços da genética nas últimas décadas, cujos desdobramentos éticos ainda são pouco conhecidos (McNAMEE et al., 2009; WAGNER, 2013). Nesse contexto, é bastante utilizado o teste genético de tipagem de hemoglobinas, capaz de identificar pessoas com a anemia ou com o traço falciforme. Tendo em vista a elevada prevalência da doença e do traço falciforme na população negra, as associações esportivas de alguns países, como Brasil e Estados Unidos, têm buscado identificar esportistas com o traço falciforme, e foi esse o caso da atleta. Ela declarou à mídia como foi o recebimento dos resultados da pesquisa genética sobre suas hemoglobinas:

[...] o médico me chamou com toda a comissão técnica. Disse que poderia seguir a carreira, mas que não poderia jogar na altitude. [...] [A atleta relata também qual foi a sua reação imediata]. Foi como se perdesse um parente próximo. Eu vinha treinando bem. [...] [E informa o que pretende fazer]. O baque foi grande, mas eu pretendo continuar no futebol (LEONE, 2010).

Por ter sido identificada com o traço falciforme e sob a justificativa de ser essa uma característica genética supostamente proibitiva para “jogar na altitude”, a atleta foi eliminada da seleção pela equipe técnica da CBF. Entretanto, desempenhar atividades esportivas, seja amadora, seja profissionalmente, não é um impedimento às pessoas com o traço falciforme, pois, segundo documento 
do Ministério da Saúde, “[...] o indivíduo portador do traço pode fazer qualquer modalidade esportiva, já que não há dados epidemiológicos consistentes que impeçam a prática de qualquer esporte" (BRASIL, 2009, p. 31). O documento foi produzido como resultado de debates entre profissionais e pesquisadores especialistas em doenças falciformes do Brasil e do exterior. Segundo ele, a literatura internacional não apresenta evidências suficientes de pesquisas que indiquem ser a atividade física nociva à saúde de pessoas com traço falciforme, salvo em condições extenuantes e sem hidratação adequada, em que cuidados preventivos são recomendados a todas as pessoas, independentemente de suas características genéticas ou da intensidade da prática (BRASIL, 2009). Essa interpretação é compartilhada pelos National Institutes of Health (NIH), que, em 2002, já tinham declarado por meio de uma publicação: “[...] o traço falciforme não impede a participação em esportes competitivos. [...] Trabalhos científicos mostram que não há aumento de morbidade ou mortalidade entre atletas profissionais com o traço" (NIH, 2002, p. 16). Nesse sentido, a eliminação da atleta pela equipe técnica da CBF não encontra fundamento na literatura científica nem na posição técnica do Ministério da Saúde ou de outras instituições internacionais de pesquisa.

Segundo Diver e Cohen (2001), um dos receios populares relativos ao rastreamento genético tem como fundamento a preocupação de que a informação genética seja disponibilizada a terceiros sem o devido consentimento, culminando em ações discriminatórias. Nesse sentido, a narração da atleta sobre como recebeu o resultado de seu teste, seguido do comunicado referente a sua saída da seleção, é outro dado que revela os limites da CBF em lidar com a descoberta do traço falciforme. A informação sensível sobre a descoberta do traço foi apresentada na presença de "toda a comissão técnica" e ultrapassou, portanto, os limites do consultório e da relação de confidencialidade que poderia ter sido preservada entre o profissional de saúde e a atleta. Ao ter o resultado de seu exame divulgado para um grupo de pessoas, a atleta teve também negado seu direito à privacidade.

$\mathrm{O}$ traço falciforme é uma informação genética com potencial de gerar discriminação e trazer prejuízos no mundo do trabalho e dos estudos, bem como de dificultar o acesso a planos de saúde ou seguros de vida privados (GUEDES; DINIZ, 2007; WAGNER, 2013). Em se tratando de mulheres com o traço falciforme, há ainda a possibilidade de a informação ser utilizada para discutir 
ou até mesmo induzir escolhas reprodutivas (GUEDES, 2012; TAYLOR; KAVANAGH; ZUCKERMAN, 2014). No caso da atleta, o traço falciforme encontrado serviu para eliminá-la da seleção. Não há informação de que a atleta teria recebido, por exemplo, um aconselhamento genético, que é o procedimento técnico por meio do qual um profissional de saúde, com formação e treinamento para esse fim, explica o resultado do teste e esclarece dúvidas. Segundo Heather Quick (2012), a adoção de testes para o traço falciforme no meio esportivo não pode prescindir de cuidados voltados à preservação da privacidade dos atletas, de modo a evitar discriminação. Na impossibilidade de adotar mecanismos eficazes de proteção à privacidade, Quick (2012) propõe que esse tipo de teste não seja realizado. O modo como a atleta foi comunicada do resultado de seu teste e eliminada da seleção sugere que a CBF não possuía um protocolo de atendimento estabelecido para uso de testes genéticos e desconhecia cuidados éticos básicos para a proteção de suas atletas.

O comunicado da equipe técnica sobre o resultado do teste traz ainda um prognóstico confuso sobre repercussões do traço falciforme. Segundo afirmou a atleta em reportagem, o porta-voz da notícia sobre o traço e a eliminação "disse que [ela] poderia seguir carreira, mas não poderia jogar na altitude”. Essa era uma informação de difícil entendimento, sobretudo no caso de uma atleta cuja experiência profissional em quadra, durante anos, jamais tinha sido acompanhada de supostas manifestações clínicas do traço falciforme. O prognóstico sugeria, portanto, que a restrição à participação no campeonato era baseada em fatores geográficos, e não físicos. Apesar do baque da notícia, a atleta, que também era estudante universitária, não se resignou com o prognóstico e pesquisou por conta própria sobre o traço falciforme e seus desdobramentos. Segundo conta o técnico, "[...] e, como é uma menina muito inteligente e faz faculdade, tá fazendo engenharia e está no sexto semestre, ela foi fazer pesquisa e aí na própria pesquisa dela, ela percebeu que ela achava também que nada ia prejudicar a seleção [...]”.

A pesquisa feita pela atleta tranquilizou-a sobre o real significado do traço, que não poderia ser confundido com uma doença nem a impediria de seguir jogando. Após a eliminação, ela retornou ao clube estadual de origem e apenas passou a se hidratar melhor durante as atividades físicas, revela o técnico: “[...] ela mesma fazendo a pesquisa, eu acho que foi mais uma coisa individual dela, ela se preocupou mais em beber bastante água, isso ela viu na internet e foi 
isso que ela ficou fazendo, particularmente". O desenrolar do caso revela que

o teste genético serviu de fundamento para a eliminação da seleção em razão da altitude do local onde seria a competição; ou seja, a hipotética restrição não estava inscrita nas hemácias da atleta, mas no ambiente físico e na região geográfica onde ocorreria a competição.

Embora transcorridas décadas de estudos desde a descoberta da anemia falciforme e do traço falciforme, ainda é comum a confusão entre ambos, o que pode contribuir para decisões precipitadas, como a que conduziu à eliminação da atleta da seleção. Alguns profissionais de saúde, apesar de reconhecerem a diferença entre traço e anemia falciforme, enxergam ambos como se fossem sinônimos em relação às manifestações corpóreas. É o que sugere o relato de um médico em um jornal por ocasião da eliminação da atleta:

[...] quem tem o traço tem algumas hemoglobinas com formação defeituosa e a função delas é transportar oxigênio. Em grande altitude existe a diminuição da quantidade de oxigênio na atmosfera e, por isso, ela teria dificuldade de respirar, dor articular, poderia fazer trombose e ter sangramentos (LEONE, 2010).

Segundo o relato do médico, pertencente à equipe técnica de um dos maiores clubes profissionais do futebol brasileiro, o traço falciforme traria restriçōes típicas da anemia falciforme, o que tornaria o traço em si quase uma forma atenuada da doença. A narrativa médica de que o traço falciforme é um impedimento à prática profissional de esportes não encontra respaldo na literatura científica, reforça estereótipos e contribui para promover atos de discriminação nos esportes, como os que vêm ocorrendo no Brasil. A confusão entre traço e anemia falciforme persiste entre profissionais de saúde e a população em geral, o que pode ser explicado pela falta de conhecimento atualizado sobre o tema, ou mesmo ser considerado uma ação dissimulada para discriminar pessoas em razão de características raciais, econômicas e de gênero (TAPPER, 1999; WAILOO, 2001; GUEDES, 2006).

O caso da atleta, ocorrido em 2010, guarda semelhanças com o caso de outra atleta brasileira discriminada por possuir o traço falciforme. Em 2004, uma jogadora foi eliminada da seleção brasileira de vôlei sob a justificativa de que o traço representaria um risco à integridade física e ao desempenho em esportes competitivos (GUEDES; DINIZ, 2007). Ambos os casos envolveram atletas mulheres que foram afastadas sob a justificativa de um cuidado preventivo, baseado no argumento do suposto dano que surgiria da prática esportiva em regiôes de elevada altitude. ${ }^{3}$ A eliminação das atletas não se fundamentou, 
portanto, em evidências objetivas nem considerou a trajetória profissional anterior de ambas em esportes competitivos, sem manifestações clínicas atribuídas ao traço falciforme. Outra característica comum entre os casos foi o amadorismo de ambas as confederações ao revelarem os resultados dos testes, sem assegurar o direito à privacidade nem dispor, em suas equipes técnicas, de profissionais capacitados ao fornecimento do aconselhamento genético. No intervalo entre os dois casos, o tema dos testes genéticos para identificação de pessoas com o traço falciforme no meio esportivo e militar foi alvo de debates promovidos por instituições do governo brasileiro. Essas instituiçôes produziram um documento destinado a esclarecer o assunto e proteger direitos das pessoas submetidas aos testes, mas essa iniciativa se mostrou insuficiente, tendo em vista o caso envolvendo a CBF (BRASIL, 2009). A persistência de atos de discriminação nos esportes brasileiros devido ao traço falciforme exige novas e eficazes açôes voltadas ao debate sobre aspectos éticos da adoção de testes genéticos. Exige, ainda, a criação de medidas de combate ao reducionismo genético presente nas avaliações morais feitas por entidades esportivas.

Após a dispensa da seleção brasileira, a atleta retornou para o seu clube de origem determinada a superar o episódio, dar continuidade a sua trajetória profissional por meio da participação em disputas regionais e, paralelamente, seguir com seus estudos universitários. Foi obstinada em cumprir o que havia prometido em declaração ao jornal: "eu pretendo continuar jogando". No retorno a sua cidade, a atleta foi acolhida e em nenhum momento recebeu qualquer questionamento em relação a sua integridade física e seu futuro no futebol profissional. Algum tempo depois de sua volta, aceitou o convite de uma universidade dos Estados Unidos para estudar e jogar no time local. Por ocasião da entrevista com o técnico, em 2012, a atleta continuava a residir nos Estados Unidos, onde participava de campeonatos universitários e tinha cobertos os seus custos com alimentação e moradia, além de receber remuneração. Segundo relatou o técnico, nos Estados Unidos a atleta conquistou o posto de melhor jogadora da universidade, estava "jogando em várias cidades americanas, e nunca houve problema nenhum de saúde”. Seu caso, portanto, evidencia a necessidade de ampliar o debate brasileiro sobre o uso de testes genéticos e criar mecanismos de proteção de pessoas potencialmente vulneráveis a episódios de discriminação resultante de sua diversidade genotípica. 
Discriminação genética e importância de princípios da ética em pesquisa

A literatura tem chamado de "discriminação genética" casos como o da atleta brasileira de futebol impedida de jogar diante do resultado de um teste genético que não revelou doença, mas descobriu uma característica hereditária considerada ameaçadora. A discriminação genética é o conceito utilizado para classificar relações sociais de opressão em que pessoas ou famílias submetidas a testes genéticos podem ter seus direitos restringidos, dificultados ou negados devido a interpretaçōes sobre seus genótipos (GELLER, 2002; GUEDES; DINIZ, 2007). Entre os principais cenários onde a discriminação genética pode ocorrer com maior frequência, estão instituições empregadoras, sistemas educacionais, instituições de saúde, empresas de seguro de vida e forças armadas (ALBERTSON, 2008; LEMKE, 2013; QUINN; DE PAOR; BLANCK, 2015). Estudos e debates sobre a discriminação genética têm se intensificado nas últimas décadas como resultado do avanço do conhecimento no campo da genética, subsidiado por iniciativas como o Projeto Genoma Humano.

Os debates sobre discriminação genética têm contribuído para análises sobre a pertinência e abrangência desse conceito. Alguns pesquisadores criticam desde a ausência ou a escassez de evidências empíricas capazes de convencer sobre a existência da discriminação baseada em fatores genéticos até a abrangência do fenômeno e suas reais repercussões na vida de pessoas cujas informações genéticas foram divulgadas (THOMAS, 2012; JOLY et al., 2013; LEMKE, 2013; ROSE, 2013). O conceito é visto como frágil na visão de seus críticos, pois, além de não revelar um fenômeno novo, faltaria precisão ao descrever as vítimas desse tipo de discriminação — que, segundo indicam alguns estudos, podem ser pessoas sem sintomas discriminadas em razão de fatores fenotípicos e não somente do genótipo (LEMKE, 2013). Ou seja, o que por vezes se denomina como discriminação genética poderia ser descrito também como discriminação racial, econômica ou de gênero.

No caso analisado neste artigo, defendemos que a atleta foi vítima de discriminação genética por ter sido eliminada após o resultado de um teste genético, e por não existirem outros fatores conhecidos que justificariam a decisão da CBF. O futebol brasileiro apresenta um histórico de discriminação racial que 
persiste e envolve clubes esportivos e torcedores (FILHO, 2010). Entretanto, analisando o caso da atleta e o perfil da seleção feminina de futebol, não encontramos evidências para o argumento de que a eliminação foi motivada por injúria racial. A discriminação de gênero seria outro fator a ser considerado, visto que pesquisas revelam o caso de atletas submetidas a checagem da autenticidade do sexo, uma espécie de "verificação do gênero" feita em atletas do sexo feminino e considerada um ato sexista (HEGGIE, 2010). Não há registro, entretanto, de que esse tipo de procedimento tenha sido empregado com a atleta brasileira.

Já fatores como a condição econômica ou mesmo a naturalidade da atleta não foram declarados como critérios de seleção. Apesar de julgamentos subjetivos existirem, a depender do clube de origem das atletas, a naturalidade, a faixa etária e a condição econômica em princípio não seriam impedimentos à convocação e à participação na seleção brasileira feminina de futebol. A atleta brasileira foi impedida de jogar porque interpretaram seu traço falciforme como um risco ao desempenho físico em região com elevada altitude, como é o caso do Equador, onde ocorreria a disputa. Essa interpretação pode ter sido motivada por desconhecimento ou até mesmo intencionalmente, com o objetivo de beneficiar outras atletas num cenário com ampla oferta de escolhas. Porém, o fundamento da eliminação foi o resultado de um teste genético, o que justifica a classificação desse caso como um ato de discriminação genética.

A decisão de eliminar a atleta talvez não existisse ou mesmo poderia ser imediatamente contestada após a sua divulgação caso o Brasil possuísse medidas de proteção aos direitos de pessoas submetidas a testes genéticos. Ainda são poucas e frágeis as iniciativas brasileiras voltadas à prevenção da discriminação genética, entre as quais se destacam: a Constituição Federal de 1988; a publicação do Ministério da Saúde intitulada Consenso Brasileiro sobre Atividades Esportivas e Militares e Herança Falciforme no Brasil-2007; e o Projeto de Lei no 4.610/1998, do Congresso Nacional.

O texto constitucional de 1988 assegura direitos fundamentais em seu artigo $5^{\circ}$, entre eles o direito à privacidade; porém, não faz referência direta ao fenômeno da discriminação genética com suas especificidades (BRASIL, 1988b). A publicação do Ministério da Saúde foi uma ação pioneira no combate à discriminação de pessoas com traço falciforme nos meios esportivos e militares, mas o texto tem papel apenas educativo, restringindo-se a informar que traço 
falciforme não é doença e que pessoas com esse tipo de diversidade genética podem praticar esportes sem a obrigatoriedade de se submeter a testes (BRASIL, 2009). O texto ministerial não indica, por exemplo, os cuidados éticos necessários se testes forem realizados para identificação do traço falciforme. Além disso, é um documento ainda pouco divulgado para o público-alvo (atletas, entidades esportivas e mídia), o que contribui para a persistência da discriminação de atletas com o traço falciforme nos esportes. O Projeto de Lei no 4.610/1998 é a iniciativa mais direcionada ao combate da discriminação genética, como indica sua ementa:

[...] estabelece que a realização de testes preditivos de doenças genéticas ou que permitam a identificação de pessoa portadora de um gene responsável por uma doença ou pela suscetibilidade ou predisposição genética a uma doença só é permitida com finalidades médicas ou de pesquisa médica e após aconselhamento genético, por profissional habilitado (BRASIL, 1998, p. 1).

Entretanto, esse projeto tramita no Congresso Nacional há mais de 15 anos e, embora esteja na fila de espera para entrar na pauta do plenário desde 2008, ainda não foi considerado uma prioridade dos parlamentares, apesar dos casos registrados de discriminação genética no Brasil na última década.

Estabelecer leis como forma de prevenir a discriminação genética é uma medida considerada controversa entre os pesquisadores. Os críticos das leis de discriminação genética afirmam que essas medidas podem reforçar o essencialismo genético, o que contribuiria para fortalecer o mito das profecias genéticas com seus determinismos, no lugar de combatê-los; criar status e proteção diferenciada para a informação genética, distinguindo-a das demais informações em saúde com semelhante potencial de gerar discriminação; e camuflar outros tipos de discriminação presentes nas relações sociais historicamente, como a racial e a de gênero, que passariam a ser consideradas genéticas ao focarem na centralidade dos testes e seus resultados, sem levar em conta outros fatores do contexto (LEMKE, 2013). Alguns estudos sugerem que as leis de combate à discriminação genética podem ser um exagero diante da real dimensão do fenômeno, e existem pesquisadores que consideram a discriminação genética moralmente defensável e legítima para regular decisões e subsidiar planejamentos econômicos (DIVER; COHEN; 2001; THOMAS, 2012).

Apesar das críticas, é crescente o número de países que, como os Estados Unidos, adotaram leis de combate à discriminação genética nos últimos anos. Segundo o sociólogo Nikolas Rose, "França, Noruega, Austrália, Dinamarca, 
Países Baixos e Áustria têm aprovado leis que tanto limitam severa quanto terminantemente o uso de informação derivada de testes genéticos para quaisquer outros fins que não os médicos ou científicos [...]” (2013, p. 171). O desafio das leis de discriminação genética está em não se fixar nos aspectos punitivos, mas promover também práticas educativas e princípios éticos favoráveis à proteção de pessoas submetidas aos testes.

A observância de princípios da ética em pesquisa é uma medida de proteção que não foi adotada no caso da atleta. Uma etapa de consentimento prévio em que fossem explicados os objetivos do teste para identificação do traço falciforme e, em seguida, o fornecimento de aconselhamento genético seriam dois requisitos capazes de atenuar o impacto da notícia na vida pessoal e profissional da atleta.

A pesquisa médica da $\mathrm{CBF}$ para identificação do traço falciforme não se justifica por razões terapêuticas, visto que o traço falciforme não era uma doença a ser tratada. O Ministério da Saúde inclusive declara que "não é necessário fazer triagem para hemoglobinopatias em indivíduos que queiram praticar esportes, quer de natureza amadora ou profissional” (BRASIL, 2009, p. 31). Nem mesmo a alegação de que o teste foi realizado para proteger a atleta de um suposto risco geográfico representado pela altitude do local onde ocorreria a competição se justificaria, pois, segundo o Ministério da Saúde, não existe essa diferenciação:

[...] é fundamental que se esclareça entre os mais diferentes segmentos da sociedade que a heterozigose para a hemoglobina $S$ não confere ao seu portador maior risco que a população geral no que tange às atividades físicas, desde que atendidas as condições básicas de hidratação e de descanso (BRASIL, 2009, p. 31).

Considerando-se que a pesquisa médica para identificar o traço falciforme não era voltada para a assistência em saúde, os testes para identificação de hemoglobinas somente poderiam ter sido realizados se houvesse um protocolo de pesquisa que cumprisse todas as exigências da Resolução no 466/2012 (BRASIL, 2013). E, ainda usando como referência as declarações do Ministério da Saúde sobre o traço falciforme, as atletas identificadas com o traço falciforme não poderiam receber tratamento diferenciado das demais atletas, pois o traço não seria sinônimo de "maior risco".

A Resolução no 466/2012 apresenta princípios da ética em pesquisa e uma série de requisitos que deveriam ser cumpridos em investigações feitas sobre o traço falciforme pelas confederações esportivas no Brasil. Uma pesquisa médica envolvendo atletas testadas para a identificação do traço falciforme sem finalidade 
terapêutica é, ainda assim, uma pesquisa. Portanto, deveria ser responsabilidade

das confederações esportivas, responsáveis pelo rastreamento genético em atletas, preparar um protocolo de pesquisa e submetê-lo à avaliação de um CEP antes de iniciar investigações eticamente duvidosas e com potencial de gerar discriminação. No protocolo, deveria constar a descrição dos responsáveis pelo estudo, bem como os métodos, os resultados esperados, os riscos envolvidos e a assistência a ser prestada aos indivíduos que voluntariamente aceitassem participar, mediante consentimento prévio que assegurasse o sigilo de sua identidade. Além disso, o uso de testes genéticos exige a presença de profissionais capacitados no fornecimento de assistência específica antes e após o estudo, tendo em vista as especificidades da informação genética e seus desdobramentos na vida de uma pessoa (SALM et al., 2014). A informação de que os resultados dos testes serviriam para fins de seleção de atletas e poderiam ser divulgados para toda a equipe técnica sem preservar a identidade das participantes no estudo também é um aspecto que deveria constar no protocolo de pesquisa a ser avaliado pelo CEP.

Essa resolução vem sendo criticada majoritariamente por pesquisadores das Ciências Humanas e Sociais que não se encontram representados num conjunto de regras inspirados nos modelos de pesquisas das áreas biomédicas. $\mathrm{O}$ caso relatado neste artigo sugere que a referida resolução também pode ser alvo de resistência ou revelar a negligência de pesquisadores da medicina esportiva que não se submetem às regras estabelecidas por ela e realizam pesquisas em suas instituições de saúde, como os serviços médicos das confederações esportivas. ${ }^{4}$ Entretanto, a difusão de pesquisas com uso de testes genéticos nos esportes não pode prescindir da observância de cuidados éticos capazes de assegurar direitos fundamentais dos atletas, sendo esse um consenso no debate internacional sobre o tema (GUEDES; DINIZ, 2007; McNAMEE et al., 2009; QUICK, 2012; WAGNER, 2013; QUINN; DE PAOR; BLANCK, 2015). Ela pode ser considerada um instrumento útil de proteção aos direitos das pessoas envolvidas em pesquisas genéticas desde que também aplicada aos profissionais da medicina esportiva que fazem pesquisa em seus consultórios.

Apesar da urgência de contemplar especificidades das diferentes áreas do saber, com suficiente representatividade dessas áreas na composição dos CEPs e do Conselho Nacional de Ética em Pesquisa, a Resolução no 466/2012 tem o mérito de estabelecer cuidados éticos necessários ao aperfeiçoamento das 
pesquisas com testes genéticos no meio esportivo brasileiro. Entretanto, existe um desafio anterior, de os profissionais da medicina esportiva refletirem sobre suas práticas de rastrear atletas com o traço falciforme e o reconhecerem como um procedimento de pesquisa que deveria ser pautado na observância de princípios éticos voltados à proteção de direitos fundamentais.

\section{Considerações finais}

Analisar um caso de discriminação genética no âmbito esportivo brasileiro permitiu evidenciar algumas das consequências do descumprimento de diretrizes da ética em pesquisa nas investigações médicas com uso de testes genéticos. Assim, este artigo abordou as repercussões nocivas de um teste genético na vida profissional de uma atleta vítima da prática do reducionismo genético, evidenciado por meio de um prognóstico baseado em fundamentos morais. Nessa perspectiva, observou-se que, embora exista no Brasil a Resolução no 466/2012, que determina parâmetros éticos de pesquisas envolvendo seres humanos, há descumprimento ou mesmo desconhecimento da adoção de medidas voltadas à proteção das pessoas submetidas a testes para pesquisas genéticas.

A legislação brasileira é ainda insuficiente para tratar do uso incontrolado de testes genéticos e não prevê mecanismos de prevenção da discriminação de pessoas submetidas a pesquisas com uso de informações sensíveis em saúde. $\mathrm{O}$ caso de discriminação da jogadora de futebol suscita o desafio de combinar os avanços diagnósticos da era de descobertas genéticas com a garantia e preservação de direitos humanos. $\mathrm{O}$ tratamento dado à atleta revela, ainda, a urgência de contestar narrativas sobre o corpo com traço falciforme e outros tipos de diversidade existencial, que fundamentam profecias genéticas capazes de gerar opressão e preservar relaçôes de desigualdade social. ${ }^{5}$

\section{Referências}

ABADIE, R. The professional guinea pig: big pharma and the risky world of human subjects. Durham and London: Duke University Press, 2010. 184p.

ALBERTSON, L. Genetic discrimination. New York: Nova Science, 2008. 113p.

AMERICAN COLLEGE OF SPORTS MEDICINE (ACSM). Active individuals with sickle cell trait: current comment. Indianapolis, 1997. 
BERGERON, M. et al. Youth football: heat stress and injury risk. Medicine \& Science in Sports \& Exercise, p. 1421-1430, 2005.

BLANCK, P.; DE PAOR, A. US legislative and policy response: some historical context to GINA. In: QUINN, G.; DE PAOR, A.; BLANCK, P. Genetic discrimination: transatlantic perspectives on the case for a European level legal response. London, New York: Routledge, 2015. p. 97-113.

BRASIL. Câmara dos Deputados. Projeto de Lei $n^{\circ}$ 4.610. Define os crimes resultantes de discriminação genética. Brasília, 1998.

BRASIL. Ministério da Saúde. Conselho Nacional de Saúde. Resolução n. 1. Aprova as normas de pesquisa em saúde. Brasília, 1988a.

Resolução no 466/2012. Aprova as diretrizes e normas regulamentadoras de pesquisas envolvendo seres humanos. Diário Oficial da União, 13 jun. 2013.

BRASIL. Ministério da Saúde. Secretaria de Atenção à Saúde. Departamento de Atenção Especializada. Consenso brasileiro sobre atividades esportivas e militares e herança falciforme no Brasil-2007. Brasília, 2009.

BRASIL. Presidência da República. Constituição da República Federativa do Brasil. Brasília, DF: Senado Federal, 1988b.

COSTA, S. O desafio da ética em pesquisa e da bioética. In: DINIZ, D. et al. (Org.). Ética em pesquisa: temas globais. Brasília: EdUnB, 2008. p. 25-52.

DE PAOR, A. Employment practices in a new genomic era: acknowledging competing rights and striking a balance. In: QUINN, G.; DE PAOR, A.; BLANCK, P. Genetic discrimination: transatlantic perspectives on the case for a European level legal response. London, New York: Routledge, 2015. p. 161-176.

DINIZ, D. et al. (Org.). Ética em pesquisa: temas globais. Brasília: EdUnB, 2008.

DIVER, C.; COHEN, J. Genophobia: what is wrong with genetics discrimination? University of Pennsylvania Law Review, v. 149, p. 1439-1482, 2001.

FILHO, M. O negro no futebol brasileiro. 5. ed. Rio de Janeiro: Mauad, 2010. 344p.

FLEISCHER, S.; SCHUCH, P. Antropologia, ética e regulamentação. In: . (Org.).

Ética e regulamentação na pesquisa antropológica. Brasília: EdUnB, 2010. p. 9-21.

GELLER, L. Current developments in genetic discrimination. In: ALPER, J. et al. (Eds.). The double-edged helix: social implications of genetics in a diverse society. Baltimore: The Johns Hopkins University Press, 2002. p. 267-285.

GUEDES, C. Decisões reprodutivas e triagem neonatal: a perspectiva de mulheres cuidadoras de crianças com doença falciforme. Ciência e Saúde Coletiva. Rio de Janeiro, v. 17, p. 2367-2376, 2012. 
O campo da anemia falciforme e a informação genética: um estudo sobre o aconselhamento genético. Dissertação (Mestrado em Ciências Sociais) — Instituto de Ciências Sociais, Universidade de Brasília, Brasília, 2006.

GUEDES, C.; DINIZ, D. A ética na história do aconselhamento genético: um desafio à educação médica. Revista Brasileira de Educação Médica, v. 33, p. 247-252, 2009.

. Um caso de discriminação genética: o traço falciforme no Brasil. Physis: Revista de Saúde Coletiva. Rio de Janeiro, v. 17, n. 3, p. 501-520, 2007.

GUILHEM, D.; GRECO, D. A Resolução CNS n. 196/96 e o Sistema CEP/CONEP. In: DINIZ, D. et al. (Org.). Ética em pesquisa: temas globais. Brasília: EdUnB, 2008. p. 87-121. HEGGIE, V. Testing sex and gender in sports: reinventing, reimagining and reconstructing histories. Endeavour, v. 34, n. 4, p. 157-163, 2010.

IRIART, J.; CAPRARA, A. Novos objetos e novos desafios para a antropologia da saúde na contemporaneidade. Physis: Revista de Saúde Coletiva, v. 21, n. 4, p. 1253-1268, 2011.

JOLY, Y. et al. Genetic discrimination and life insurance: a systematic review of the evidence. BMC Medicine, v. 11, n. 25, 2013.

KIM, J.; SALMAN, S.; JOLY, Y. The use of genetic information outside of the therapeutic health relationship: an international perspective. In: QUINN, G.; DE PAOR, A.; BLANCK, P. Genetic discrimination: transatlantic perspectives on the case for a European level legal response. London, New York: Routledge, 2015. p. 68-94.

LEMKE, T. Perspectives on genetic discrimination. New York, London: Routledge, 2013.

LEONE, D. Lateral baiana tem gene da anemia falciforme e foi cortada da seleção brasileira. Correio, Bahia, 18 nov. 2010.

McNAMEE, M. et al. Genetic testing and sports medicine ethics. Sports Medicine, v. 39, n. 5, p. 339-344, 2009.

MINAYO, M.; GUERRIERO, I. Reflexividade como ethos da pesquisa qualitativa. Ciência \& Saúde Coletiva, v. 19, n. 4, p. 1103-1112, 2014.

MINAYO, M. C. S. O desafio do conhecimento: pesquisa qualitativa em saúde. 10. ed. São Paulo: Hucitec, 2007. 269p.

MOUTINHO, C. et al. Dificuldades, desafios e superações sobre educação em saúde na visão de enfermeiros de saúde da família. Trabalho, Educação e Saúde, Rio de Janeiro, v. 12, n. 2, p. 253-272, maio/ago. 2014.

NATIONAL INSTITUTES OF HEALTH (NIH). The management of sickle cell disease. Bethesda: Division of Blood Diseases and Resources/NIH, 2002.

OLIVEIRA, A.; GUEDES, C. Serviço social e desafios da ética em pesquisa: um estudo bibliográfico. Revista Katálysis, v. 16, p. 119-129, 2013. 
ORLANDI, E. Análise do discurso: princípios \& procedimentos. 3. ed. Campinas: Pontes, 2001. 100p.

PAZELLO, M.; KAMEDA, K. E-saúde e desafios à proteção da privacidade no Brasil. Politics, 2013.

PEARSON, H. Sickle cell trait and competitive athletics: is there a risk? Pediatrics, v. 83, n. 4, p. 613-614, 1989.

QUICK, H. Privacy for safety: the NCAA sickle-cell trait testing policy and the potential for future discrimination. Iowa Law Review, v. 97, p. 665-691, 2012.

QUINN, G.; DE PAOR, A.; BLANCK, P. Genetic discrimination: transatlantic perspectives on the case for a European level legal response. London, New York: Routledge, 2015. 282p. ROSE, N. A política da própria vida: biomedicina, poder e subjetividade no século XXI. São Paulo: Paulus, 2013. 396p.

SALM, M. et al. Use of genetic tests among neurologists and psychiatrists: knowledge, attitudes, behaviors, and needs for training. Journal of Genetic Counseling, v. 23, n. 2, p. 156-163, 2014.

TAPPER, M. In the blood: sickle cell anemia and the politics of race. Philadelphia: University of Pennsylvania Press, 1999. 160p.

TAYLOR, C.; KAVANAGH, P.; ZUCKERMAN, B. Sickle cell trait:neglected opportunities in the era of genomic medicine. JAMA, v. 311, n. 15, 2014.

THOMAS, R. Genetics and insurance in the United Kingdom 1995-2010: the rise and fall of "scientific" discrimination. New Genetics and Society, v. 31, n. 2, p. 203-222, 2012.

VÍCTORA, C. et al. (Org.). Antropologia e ética: o debate atual no Brasil. Rio de Janeiro: EdUFF, 2004. 207p.

WAGNER, J. Playing with heart and soul... and genomes: sports implications and applications of personal genomics. PeerJ., 1:e120, 2013.

WAILOO, K. Dying in the city of the blues: sickle cell anemia and the politics of race and health. North Carolina: University of North Carolina Press, 2001.

ZAGO, M. Anemia falciforme e doenças falciformes. In: HAMANN, E.; TAUIL, P. (Org.). Manual de doenças mais importantes, por razões étnicas, na população afro-descendente. Brasília: Ministério da Saúde, 2001. p. 13-35.

\section{Notas}

${ }^{1}$ A pesquisa que gerou este artigo foi parcialmente financiada pelo $\mathrm{CNPq}$ por meio do Programa Proic/CNPq da Universidade de Brasília. Gostaríamos de agradecer as leituras e sugestôes recebidas de avaliadores anônimos da Revista Physis, que representaram contribuiçôes importantes para o aperfeiçoamento e a redação da versão final deste artigo. Nossa gratidão, ainda, pelos diálogos reflexivos 
envolvendo o tema e estabelecidos com Alexandre Boukai, André Rios, Debora Diniz, Helena Pimentel, Kátia Soares Braga, Isabela Vieira, Lucas Cavalcante, Marilena Correa, Marcelo Cruzick, Marcelo Medeiros, Melissa Creary, Roberto Abadie, Roberto Menezes, Sérgio Ibiapina Costa, Silvia Regina Brandalise, Thomas Lemke, Victor Ferraz, Vítor Pereira e Ximena Pamela Bermúdez. Agradecemos também a revisão de língua portuguesa e de forma realizada por Ana Terra e Ana Silvia Gesteira.

${ }^{2} \mathrm{O}$ antropólogo Roberto Abadie (2010), em seu livro The professional guinea pig: big pharma and the risky world of human subjects, revela como as proibições de regulamentação interna da ética em pesquisa podem ser relativizadas. No artigo de abertura deste dossiê, Abadie explora um dos interditos estabelecidos pelo sistema brasileiro de revisão ética em pesquisa: a remuneração de participantes. $\mathrm{O}$ autor mostra, em seu artigo, como o pagamento dos participantes de um estudo é uma possibilidade em outros países e como a remuneração não pode ser entendida como sinônimo de exploração ou desrespeito a direitos.

${ }^{3}$ A literatura internacional apresenta relatos de discriminação de mulheres com o traço falciforme principalmente no mundo do trabalho. A lei de combate à discriminação genética dos Estados Unidos teve como uma de suas fontes de inspiração os casos de discriminação envolvendo pessoas com o traço falciforme desde a década de 1970. Em 1998, ocorreu um caso paradigmático envolvendo mulheres negras estadunidenses que foram submetidas a testes genéticos e prejudicadas em seus locais de trabalho após serem identificadas com o traço falciforme; mesmo em outros países, há registro de discriminação contra trabalhadores com herança genética falciforme, como ocorreu na Austrália em 2005 (BLANCK; DE PAOR, 2015; DE PAOR, 2015; KIM; SALMAN; JOLY, 2015). No Brasil, não há relatos conhecidos de discriminação genética no acesso a serviços de saúde, o que pode ser explicado pela existência de um sistema de saúde com cobertura universal; porém, os registros brasileiros de discriminação contra mulheres negras identificadas com traço falciforme exibem um perfil que coincide com o da história registrada nos Estados Unidos (GUEDES; DINIZ, 2007).

${ }^{4}$ Os autores desconhecem a justificativa para a pesquisa voltada à identificação de atletas com o traço falciforme ser adotada como um procedimento por setores da medicina esportiva brasileira. Sugerimos que pesquisas futuras sobre discriminação genética elejam, entre os seus objetivos, conhecer as motivações que levam profissionais dos esportes a identificar e até eliminar atletas com o traço falciforme de competições. Explorar o universo dos avanços da genética e seus desdobramentos nas sociedades contemporâneas tem sido apontado por diferentes campos do saber como uma das prioridades da agenda de pesquisa e, nesse cenário, faltam estudos empíricos sobre motivações profissionais capazes de promover a ocorrência de casos de discriminação genética (IRIART; CAPRARA, 2011; QUINN; DE PAOR: BLANCK, 2015).

${ }^{5}$ C. Guedes realizou o trabalho de campo e D. Reis fez a transcrição das entrevistas. A análise de dados e redação do artigo foi feita conjuntamente por ambos os autores. 


\section{Abstract}

\section{Genetic research, moral prognostic and genetic discrimination: a case study on sickle cell trait}

The debate on research ethics can be applied both to the scientific methodology as other disciplines, such as sports. In the field of Brazilian sports health, it has been common research that do genetic testing to identify athletes with sickle cell trait. Despite the persistence of Brazilian sports federations to discriminate athletes with this inherited trait, sickle cell trait is not a disease. This article reports the case of a soccer athlete victim of genetic discrimination: identified with the sickle cell trait, she was deemed unfit to participate in a championship for the Brazilian Football Confederation. The paper analyzes the implications of genetic research to identify the sickle cell trait in the absence of ethical care aimed at preserving the rights of those who submit to testing. It also shows the vulnerability to which are exposed people involved in research that do genetic testing without ethical care or even reasonable justifications and the results are interpreted under the rationality of biological determinism and genetic reductionism. Brazilian sports federations interested in identifying athletes with sickle cell trait should submit this order to study the evaluation of Research Ethics Committees, as this is a potential to cause harm to the procedure of athletes. The genetic test can not be considered an act of health care, since no disease is being treated.

> Key words: research ethics; genetic discrimination; sickle cell; sports. 


\section{ERRATA}

No artigo "Pesquisas genéticas, prognósticos morais e discriminação genética: um estudo de caso sobre traço falciforme", publicado em Physis: Revista de Saúde Coletiva, v. 25, n. 3, p. 729-751, 2015, DOI: http://dx.doi.org/10.1590/S010373312015000300004, na página 729, o resumo e as palavras-chave estão errados.

\section{ONDE SE LÊ:}

Resumo: O estudo analisou os debates, no período de 2000 a 2010, no Conselho Nacional de Saúde (CNS) e na Comissão Intersetorial de Vigilância Sanitária e Farmacoepidemiologia (CIVSF), sobre os temas da vigilância sanitária e articulação com o Conselho Consultivo da Agência Nacional de Vigilância Sanitária (Anvisa). A pesquisa documental, de natureza qualitativa, que analisou 163 atas de reuniôes do CNS e da CIVSF, e demais documentos a elas relacionados, buscou reunir informaçōes sobre o contexto político-institucional e as interfaces e conexões entre as três instâncias. Observou-se baixa inserção do tema "vigilância sanitária" na pauta do CNS e uma atuação insuficiente da CIVSF para o fortalecimento desse debate. Conclui-se pela fragilidade de integração entre o Conselho Consultivo da Anvisa e as instâncias de controle social no Sistema Único de Saúde. Esse resultado é fruto de dificuldades de comunicação interinstitucional e da baixa inserção da vigilância sanitária no SUS, historicamente construída.

> Palavras-chave: vigilância sanitária; política de saúde; participação comunitária.

\section{LEIA-SE:}

Resumo: O debate sobre ética em pesquisa pode ser aplicado tanto ao âmbito da metodologia científica como a outras áreas do saber, como é o caso dos esportes. No campo da saúde esportiva brasileira, têm sido comuns pesquisas que fazem testes genéticos para identificar atletas com traço falciforme. Apesar da persistência de confederações esportivas brasileiras em discriminar atletas com essa característica hereditária, o traço falciforme não é uma doença. Este artigo relata o caso de uma atleta de futebol vítima de discriminação genética: identificada com o traço falciforme, ela foi considerada inapta a participar de um campeonato pela Confederação Brasileira de Futebol. O artigo analisa as repercussões da pesquisa genética para identificação do traço falciforme na ausência de cuidados éticos voltados à preservação dos direitos de quem se submete aos testes. Além disso, mostra a situação de vulnerabilidade à qual estão expostas pessoas envolvidas em pesquisas que fazem testes genéticos sem cuidados éticos ou mesmo justificativas razoáveis e cujos resultados são interpretados sob a racionalidade do determinismo biológico e do reducionismo genético. As confederaçōes esportivas brasileiras interessadas em identificar atletas com o traço falciforme deveriam submeter esse objetivo de estudo à avaliação de Comitês de Ética em Pesquisa, pois esse é um procedimento com potencial de acarretar prejuízos aos atletas. O teste genético não pode ser considerado um ato de assistência em saúde, visto que não há doença a ser tratada.

> Palavras-chave: ética em pesquisa; discriminação genética; traço falciforme; esportes. 